\title{
ELECTRON TRANSFER REACTIONS IN MICROPOROUS SOLIDS
}

\author{
Progress Report
}

June 1991-May 1992

\author{
Thomas E. Mallouk \\ Department of Chemistry \\ The University of 'Texas at Austin \\ Austin, TX 78712
}

May 1992

\section{PREPARED FOR THE U.S. DEPARTMENT OF ENERGY UNDER GRANT NUMBER DE-FG05-87ER 13789}

\section{DISCLAIMER}

\begin{abstract}
This report was prepared as an account of work sponsored by an agency of the United States Governmerit. Neither the United States Government nor any agency therewf, nor any of their employees, makes any warranty, express or implied, or assumes any legal liability or responsibility for the accuracy, completeness, or usefulness of any information, apparatus, product, or process disclosed, or represerits that its use would not infringe privately owned righis. Reference herein to any specific commercial product, process, or service by trade name, trademark, manufacturer, or otherwise does not nexessarily constitute or imply its endorsement, recarmmendatior of favoring by the United States Government or any agency thereof. The views and opisuons of authors expressed herein do not necessarily state or reflect those of the United States Government or any agency thereof.
\end{abstract}


Funds provided by this DOE grant have been used to support graduate students studying the synthesis of and light-induced electron transfer reactions which occur within microporous materials. Some highlights of our progress in the last year are:

Light-induced electron transfer reactions of donor-acceptor $(D-A)$ diads in solution and at the zeolite/solution interface. We have studied electron transfer quenching of the excited state of $R u(b p y) 3^{2+}$ in aqueous suspensions of zeolites $Y, L$, and mordenite. The internal pore network of the zeolite is ion-exchanged with methylviologen cations, which quench the excited state of the surface-bound sensitizer. A detailed study of the quenching and charge recombination kinetics, using time-resolved luminescence quenching and transient diffuse reflectance spectroscopies, shows two remarkable effects: first, the excited state quenching is entirely dynamic in large-pore zeolites ( $L$ and $Y$ ), even when they are prepared as apparently "dry" powders (which still contain significant amounts of internally sited water). Second, a lower limit for the diffusion coefficient of the $\mathrm{MV}^{2+}$ ion in these zeolites, determined by this technique, is $10^{-7} \mathrm{~cm}^{2} / \mathrm{sec}$, i.e., only about one order of magnitude slower than a typical ion in liquid water, and 2-3 orders of magnitude faster than charge transfer diffusion of cations in polyelectrolyte films or membranes such as Nafion.

The rates of intramolecular electron transfer in a series of covalently linked ruthenium tris(bipyridyl) - viologen D-A moleculcs, shown below, were studied by flash

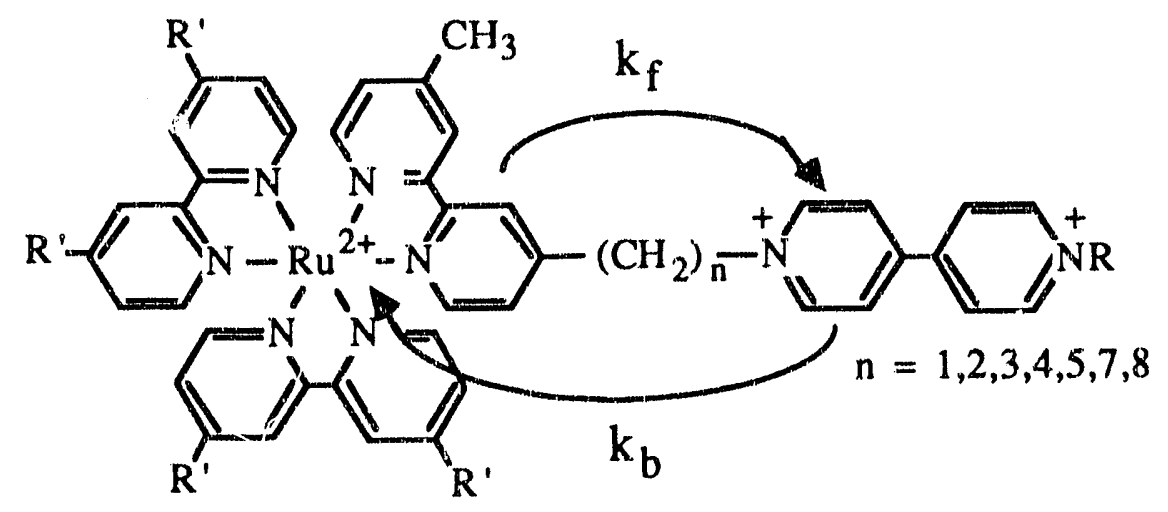

photolysis in three different media: fluid solution, solutions containing $\beta$-cyclodextrin $(\beta$ CD) as a complexing agent, and suspensions in which the molecuie was ion-exchanged onto the external surface of a large-pore zeolite. The free energy dependence of the rate constants $k_{f}$ and $k_{b}$ was studied for $n=1-2$ by varying the groups $R$ and $R^{\prime}$. The forward and back reactions occur in the normal and Marcus inverted rate regions, respectively. What is especially interesting is the distance dependence of electron transfer rates for the series $n=1-8, R=$ methyl, $R^{\prime}=H$. Both $\ln k_{f}$ and $\ln k_{b}$ vary linearly with the number of carbon atoms in the spacer chain up to $n=4$. For $n>4$ only $k_{f}$ can be measured, since $k_{b}$ is much larger than $\mathrm{k}_{\mathrm{f}}$. For these longer chain compounds $\ln \mathrm{k}_{\mathrm{f}}$ is roughly constant with $\mathrm{n}$. In the presence of $\beta-C D$, the long-chain compounds are complexed and forced into a conformation in which the donor and acceptor ends of the molecule are held apart. In this extended conformation, the $\ln \mathrm{k}_{\mathrm{f}}$ points fall roughly onto the line definedl $\mathrm{t} y \mathrm{y}$ the $n=1-5$ 
points without $\beta-C D$, so that $\ln k_{f}=26.27-1.59 n$ for the entire series, and $\ln k_{b}=25.55$ $-0.82 n$ for $n=1-4$. These results indicate that electron transfer through the saturated spacer is the dominant pathway for the $n=1-5$ molecules, ard that the through-solvent pathway becomes important only for the longest chains. Even for the longest chains $(n=7,8)$, forward and back electron transfers are rapid compared to the MLCT excited state lifetime of $\mathrm{Ru}$ (bpy) $3^{2+}$, which is ca. $700 \mathrm{~ns}$.

When these D-A molecules are ion-exchanged onto the external surfaces of largepore zeolites Y, L, and mordenite, unusually long charge-separated siate lifetimes, on the order of tens to hundreds of microseconds, are observed. The quantun. yield for charge separation is low with short chain spacers $(n=1-3)$, reaches a maximum at $n=4,5$, and decreases again for $n=7,8$. These results are interpreted in terms of folding of the $D-A$ molecule on the surface for $n=1-3$, and possibly intermolecular charge transport diffusion on the zeolite surface for longer chain compounds. The rate of back electron transfer on the surface of mordenite shows a weak dependence on chain length $n$, so that $\ln k_{b}=13.01$. $0.46 n$ for the series $n=2 .-8$. The quantum yield for charge separation is maximized for intermediate values of $n(n=4,5)$, where the spacer chain is long enough to allow the molecule to "unfold" in the zeolite channel, but not too long for rapid forward electron transfer to occur. Size-excluded solution phase donors, such as promethazine and an anionic $\mathrm{N}, \mathrm{N}^{\prime}$-dialkyl-4-methoxyaniline derivative, can quench the excited state of the $\mathrm{Ru}(\mathrm{bpy})_{3}{ }^{2+}$ moiety, allowing for improved charge separation yields in the case of long chain molecules $(n=7,8)$, and in ester-linked molecules of general formula $\left[(\text { bpy })_{2} \text { RubpyCONH }\left(\mathrm{CH}_{2}\right)_{n} \mathrm{MV}\right]^{4+}, \mathrm{n}=2,3$.

Photochemistry of Sensitized Layered Oxide Semiconductors. Last year we reported that surface sensitization of internally platinized layered oxide semiconductors such as $\mathrm{K}_{4-\mathrm{x}} \cdot \mathrm{H}_{\mathrm{x}} \mathrm{Nb}_{6} \mathrm{O}_{17} \cdot \mathrm{nH}_{2} \mathrm{O}(\mathrm{x} \approx 2.5)$ yields photocatalysts for the production of $\mathrm{H}_{2}$ and $13^{-}$in aqueous iodide solutions. Layered alkali niobates and titanates form a class of zeolitic wide-bandgap semiconductors, and are the first examples of photocatalysts that evolve hydrogen from an electrochemically reversible (i.e., non-sacrificial) electron donor with visible light excitation.

Over the past year we have conducted a detailed investigation of the mechanisms of charge separation and recombination in these materials, and have also begun studies of the photochemistry of other zeolitic oxide semiconductors. Flash photoiysis studies have shown that charge separation involves clectron injection from the sensitizer, followed by rapid reduction of the oxidized sensitizer by $I^{-}$. The $I$. initially formed in this process is very rapidly converted to $\mathrm{I}_{2}^{-}$, which then forms $\mathrm{I}_{3}{ }^{-}$in a second-order reaction. Transient spectra do not show any evidence for geminate recombination between $\mathrm{I}_{2} \cdot$ and the oxidized sensitizer, or for the formation of a geminate charge-transfer complex of these ions. Tests for dark recombination of $\mathrm{I}_{3}{ }^{-}$and $\mathrm{H}_{2}$ with these materials are negative, indicating that once chemical products are formed, they do not recombine. Apparently the lo.v quantum efficiency $(0.3 \%)$ for formation of chemical products is a consequence of recombination between conduction band electrons and $13^{\circ}$. Further evidence for this mechanism was gained from a study of hydrogen evolution from $\mathrm{M}_{4-\mathrm{x}} \mathrm{H}_{\mathrm{x}} \mathrm{Nb}_{6} \mathrm{O}_{17} \cdot \mathrm{nH}_{2} \mathrm{O}, \mathrm{M}=\mathrm{Li}, \mathrm{Na}, \mathrm{K}$, $\mathrm{Cs}$, in which the size of the hydrated alkali metal modulates the interlayer spacing of the semiconductor. It was found that the hydrogen evolution rate varied monotonically with the inverse of the layer spacing, indicating that electron tunnelling between layers is the rate-limiting step in hydrogen evolution. We are currently studying the incorporation of spacer ions that will enhance the mobility of electrons between layers, and the use of nonelectroactive adsorbates that can block access of $\mathrm{I}_{3^{-}}$to the surface. We are also investigating the possibility of overcoming the two-dimensional conductivity problem by 
using other microporous oxide semiconductors, such as hollandite, which have threedimensional tunnel structures.

Publications acknowledging DOE support, 1991-92:

J. S. Krueger and T. E. Mallouk "Redox Catalysis and Photochemistry in Zeolites," in Kinetics and Catalysis in Microheterogeneous Media, M. Grätzel and K.

Kalyanasundaram, Eds., Marcel Dekker, New York, 1991, pp. 461-490.

A. J. Bard and T. E. Mallouk, "Electrodes Modified with Clays, Zeolites, and Related Microporous Solids," accepted for publication in R. W. Murray, Ed., "Molecular Design of Electrode Surfaces."

Y. I. Kim, R. L. Riley, E. H. Yonemoto, D. Rong, and T. E. Mallouk, "Self-Assembling Electron Transport Chains in Zeolites: Molecular Rectifiers and Photodiodes," ACS Symposium Series (Supramolecular Architecture: Tailoring Structure and Function of Extended Assemblies), T. Bein, Ed., American Chemical Society: Washington, DC, in press.

Y. I. Kim, S. Salim, M. J. Huq, and T. E. Mallouk, "Visible Light Photolysis of Hydrogen Iodide Using Sensitized Layered Semiconductor Particles," J. Am. Chem. Soc., $113,9561-9563$ (1991).

Y.I. Kim, R. L. Riley, M. J. Huq, S. Salim, A. N. Le, and T. E. Mallouk, "Zeolitic Materials as Organizing Media for Semiconductor-Based Artificial Photosynthetic Systems," in Synthesis/Characterization and Novel Applications of Molecular Sieve Materials, R. L. Bedard, Ed., Materials Research Society: Pittsburgh, PA, 1991, pp. 145156.

Y. I. Kim and T. E. Mallouk, "Dynamic Electron Transfer Quenching of the Tris(2,2'bipyridyl)ruthenium(II) MLCT Excited State by Intrazeolitic Methylviologen Ions," J. Phys. Chem, 26, 2897-2885 (1992).

E. H. Yonemoto, R. L. Riley, S. J. Atherton, R. S. Schmehl, and T. E. Mallouk, "Photoinduced Electron Transfer in Covalently Linked Ruthenium Tris(bipyridyl) Viologen Molecules: Observation of Back Electron Transfer in the Marcus Inverted Region," submitted to J. Am. Chem. Soc.

\section{Plans for Research During the Ccming Year}

Work is ongoing in the two areas described above, as well as on other projects involving electron transfer in zeolitic solids. We are carrying out solid-state NMR experiments aimed at determining the conforrnation of $\mathrm{Ru}(\mathrm{bpy})_{3}$-viologen $\mathrm{D}$-A molecules on zeolite surfaces. Using isotopically labeled compounds and paramagnetic probes, we hope to deternine quantitatively the relationship between spacer length and the tendency of the molecule to "unfold" in the zeolite channels. We are also attempting to construct D'-DA-A systems of this type, in which the central D-A diad is covalently linked, and the flanking donor and acceptor are kept respectively outside and inside the zeolite pore network by size exclusion and ion exchange equilibria. We are now preparing systems in 
which immobilized donor molecules on a separate solid phase, such as polymer-modified silica, act as the ultimate source of electrons for the zeolite-bound $D^{\prime}-\mathrm{D}-\mathrm{A}-\mathrm{A}^{\prime}$ assembly. The goal of this work is to identify conditions that will extend the lifetime of charge separation from the roughly $10^{-4}$ seconds found for simple D-A diads to timescales of seconds or longer. These multicomponent molecular systems will also be tested for photochemical hydrogen evolution using internally platinized zeolite samples. Finally, we are conducting experiments aimed at quantitatively determining the rates of counterion motion, which could limit electron transfer rates in zeolite channels, and rates of exchange of complex cations between zeolite particles.

We are continuing studies of oxide semiconductors grown in/on zeolites from: molecular precursors. Last year we reported that $\mathrm{TiO}_{2}$, grown in/on platinized mordenite, mediated electron transfer between adsorbed $\mathrm{Ru}\left(\mathrm{bpy}[\mathrm{COOH}]_{2}\right)_{3}^{2+}$ and internally sited viologen cations. This system evolves hydrogen photochenuically using sacrificial electron donors, but not with chemically reversible donors. The problem in this case was traced to mediation of the recombination reaction by $\mathrm{TiO}_{2}$. It is anticipated that semiconductors with more negative conduction bandedge potentials should not mediate reverse electron transfer, and accordingly we have now prepared quantum-size $\mathrm{Nb}_{2} \mathrm{O}_{5}$ in mordenite. In the coming year we will test this and other wide-bandgap semiconductors (possibly including compound semiconductors such as $\mathrm{MTiO}_{3}, \mathrm{M}=\mathrm{Mg}, \mathrm{Ca}$ ) in donor-semiconductoracceptor-catalyst intrazeolite systems.

We are continuing work on sensitized layered oxide semiconductor systems, particularly $\mathrm{K}_{4} \mathrm{Nb}_{6} \mathrm{O}_{17}$ and $\mathrm{KTiNbO}_{5}$. In order to improve the quantum efficiency for $\mathrm{HI}$ photolysis, we are attempting to pillar these layered structures with species that may assist interlayer electron tunnelling. Potential candidates are simple ions such as $\mathrm{Zn}^{2+}, \mathrm{Cd}^{2+}$ and $\mathrm{Sc}^{3+}$, as well as small oxide $\left(\mathrm{TiO}_{2}, \mathrm{Nib}_{2} \mathrm{O}_{5}, \mathrm{WO}_{3}\right.$, etc.) semiconductor particles. We are also screening potential adsorbate molecules that could inhibit the recombination reaction between $\mathrm{I}_{3}-$ and conduction band electrons. We have begun an investigation of tunnel structure oxide semiconductors, such as titanium and titanium-niobium hollandites, in which electronic conduction is expected to be more isotropic. The problem in this case is that the tunnels are too small to allow introduction of catalysts, such as Pt clusters, from molecular precursors. We are therefore now attempting to synthesize titanium and niobium oxide semiconductors in other (larger) tunnel structures, such as psilomelane. 
DATE

FILMED

8127192 
1 